\title{
Mentoring Relationships and Programs for Youth
}

\author{
Jean E. Rhodes ${ }^{1}$ and David L. DuBois ${ }^{2}$ \\ ${ }^{1}$ University of Massachusetts, Boston, and ${ }^{2}$ University of Illinois at Chicago
}

\begin{abstract}
Mentoring is one of the most popular social interventions in American society, with an estimated three million youth in formal one-to-one relationships. Studies have revealed significant associations between youth involvement in mentoring relationships and positive developmental outcomes. These associations are modest, however, and depend on several intervening processes. Centrally important is the formation of close, enduring connections between mentors and youth that foster positive developmental change. Effects of mentoring programs likewise typically have been small in magnitude, but they increase systematically with the use of program practices likely to support relationship development. Gaps between research and practice are evident both in the indiscriminate use of the term mentoring in the prevention field and in a focus on the growth and efficiency of mentoring programs at the expense of quality. Continued expansion of effective mentoring will require a better alignment of research and practice.
\end{abstract}

KEYWORDS-mentoring; preventive intervention; nonparent adults; youth

Organized approaches to mentoring youth in the United States date back to reform-oriented initiatives in the juvenile court system more than a century ago. These efforts gave rise to Big Brothers Big Sisters of America (BBBSA), the largest and most well-known program of its kind. The past decade has witnessed a remarkable proliferation of similarly focused programs that pair caring, adult volunteers with youth from at-risk backgrounds. An estimated three million youth are in formal one-toone mentoring relationships in the United States, and funding and growth imperatives continue to fuel program expansion (MENTOR, 2006). Even larger numbers of youth report experiencing mentoring relationships outside of these types of

Address correspondence to Jean Rhodes, Department of Psychology, University of Massachusetts, 100 Morrissey Blvd, Boston, MA 02125; e-mail: jean.rhodes@umb.edu. programs with adults such as teachers, coaches, neighbors, and extended family.

Anecdotal accounts of the protective qualities of mentoring relationships and their life-transforming effects on young people abound in the media. Youth mentoring has entered the American lexicon, appearing on a U.S. postage stamp and in countless public service announcements. Federal funding for mentoring programs has increased substantially as well, with annual congressional appropriations of $\$ 100$ million since 2004 . It is only relatively recently, however, that social and behavioral scientists have focused their attention on a more rigorous examination of mentoring for children and adolescents. In this article, we review the highlights of this research. We then critically examine recent trends in practice and policy in view of current directions in research.

\section{MENTORING RELATIONSHIPS AND YOUTH OUTCOMES}

Numerous studies have examined mentoring relationships and their consequences for youth development. Illustratively, in a longitudinal study of a nationally representative sample of young adults, DuBois and Silverthorn (2005) found that those who reported having had a mentoring relationship during adolescence exhibited significantly better outcomes within the domains of education and work (high-school completion, college attendance, employment), mental health (self-esteem, life satisfaction), problem behavior (gang membership, fighting, risk taking), and health (exercise, birth control use). (They controlled where possible for the same or related measures at the start of the study as well as indices of individual and environmental risk.) The magnitude of these associations, however, was fairly small, with the reduction in risk for negative outcomes attributable to having a mentor typically less than $10 \%$. Similar findings have emerged in evaluations of programs in which mentoring relationships are arranged and supported by program staff. A meta-analysis of 55 mentoring program evaluations (DuBois, Holloway, Valentine, \& Cooper, 2002) found benefits of participation in the areas of emotional/psychological well-being, involvement in problem or high-risk behavior, and academic outcomes. Yet, in compar- 
ison to other prevention programs for children and adolescents (Durlak \& Wells, 1997), the effectiveness of mentoring programs was found to be relatively small. The few studies that collected follow-up assessments of mentoring programs revealed even weaker effects, suggesting an eroding of benefits after youth left programs and relationships with mentors ended.

More recently, Jolliffe and Farington (2007) explored the effects of youth mentoring on recidivism among juvenile offenders. Their analyses, which were based on 18 evaluations, revealed a somewhat smaller overall effect of mentoring than was reported in the meta-analysis conducted by DuBois and colleagues. Still another recent meta-analysis looked at a broader range of outcomes associated with mentoring relationships for youth across 40 investigations (Eby, Allen, Evans, Ng, \& DuBois, 2008). Results indicated that youth experiencing mentoring fared significantly better than those who did not, but the size of these differences again was relatively small and below those associated with mentoring for college students and adults.

Findings in evaluations of individual mentoring programs have also been mixed. This includes the BBBSA mentoring program. This program has been widely touted as effective based on the findings of a large, random-assignment evaluation of the program (Grossman \& Tierney, 1998). Yet the magnitude of these effects was small and generally reflected a relative slowing of negative trajectories rather than outright improvements among those receiving mentoring (Rhodes, 2002). A recent large random-assignment evaluation of BBBSA's newer, school-based mentoring program (Herrera, Grossman, Kauh, Feldman, \& McMaken, 2007) revealed similar findings. At the end of the school year, there were significant improvements in participants' academic performance, perceived scholastic efficacy, school misconduct, and attendance relative to nonmentored youth. These effects were again generally small in magnitude and, when youth were reassessed a few months into the following school year, they had for the most part eroded to nonsignificance.

Taken together, available research indicates that, although mentoring relationships can indeed promote positive development among young people, these benefits are modest in size. Nevertheless, when all relationships are combined, as in most of the analyses described above, notably more positive outcomes for some youth may be masked by neutral and even negative outcomes for youth involved in less effective mentoring relationships. For mentoring to fully realize its promise as a safe and effective intervention for young persons, programs will need to be informed by a deeper understanding of the processes that are the root of these differences.

\section{WHEN AND HOW DO MENTORING RELATIONSHIPS WORK?}

To this end, it is critically important to understand how mentoring relationships affect youth. Based on empirical and theoretical literature, Rhodes (2005) has proposed a model that delineates several processes and conditions presumed to be important for understanding the effects of mentoring relationships on youth (see Fig. 1). First and foremost, beneficial effects are expected only to the extent that the mentor and youth forge a strong connection that is characterized by mutuality, trust, and empathy (component $a$ in Fig. 1). For this type of bond to arise, mentors and youth are likely to need to spend time together on a consistent basis over some significant period of time (Spencer, 2007). Only then may youth derive significant benefits. In a reanalysis of data from the previously noted evaluation of the BBBSA program, for example, positive effects on youth outcomes became progressively stronger as relationships persisted for longer periods of time and were greatest when relationships lasted at least 1 year (Grossman \& Rhodes, 2002). For youth in relationships that terminated prematurely within the first 6 months (i.e., less than half the 1 -year commitment that volunteers were asked to make), there were no clear benefits and, in at least one instance (alcohol use), a significant increase in problems relative to a randomly assigned control group. Beyond issues of time, research indicates that the extent to which mentors and youth establish a strong connection is influenced by the dynamics of their interactions with each other. Langhout, Rhodes, and Osborne (2004), for example, found that outcomes were most favorable when youth reported experiencing not only support but also some degree of structure in their relationships with their mentors. In general, close and enduring ties appear to be fostered when mentors adopt a flexible, youth-centered style in which the young person's interests and preferences are emphasized, rather than when they focus predominantly on their own agendas or expectations for the relationship (Morrow \& Styles, 1995).

As shown in Figure 1, well-established mentoring relationships may contribute to positive youth outcomes through three interacting developmental processes: social-emotional, cognitive, and identity-related. There are several ways in which the social-emotional development of children and adolescents may be furthered through mentoring (path $b$ in Fig. 1). By serving as a sounding board and providing a model of effective adult communication, for example, mentors may help youth to better understand, express, and regulate their emotions (Rhodes, Grossman, \& Resch, 2000).

The model further assumes that positive socio-emotional experiences with mentors can generalize, enabling youth to interact with others more effectively (path $c$ ). In support of this prediction, benefits of mentoring relationships have been indicated to accrue in part through improvements in youths' perceptions of their parental relationships as well as their relationships with peers and other adults in their social networks (Rhodes, Reddy, \& Grossman, 2005; Rhodes et al., 2000). Mentoring relationships similarly may affect a range of cognitive developmental processes (path $d$ ). This aspect of the model is derived from theory and research that highlights the role of social support from adults in fostering cognitive gains during development. In particular, through interactions with mentors, children and adolescents may acquire and refine new thinking 


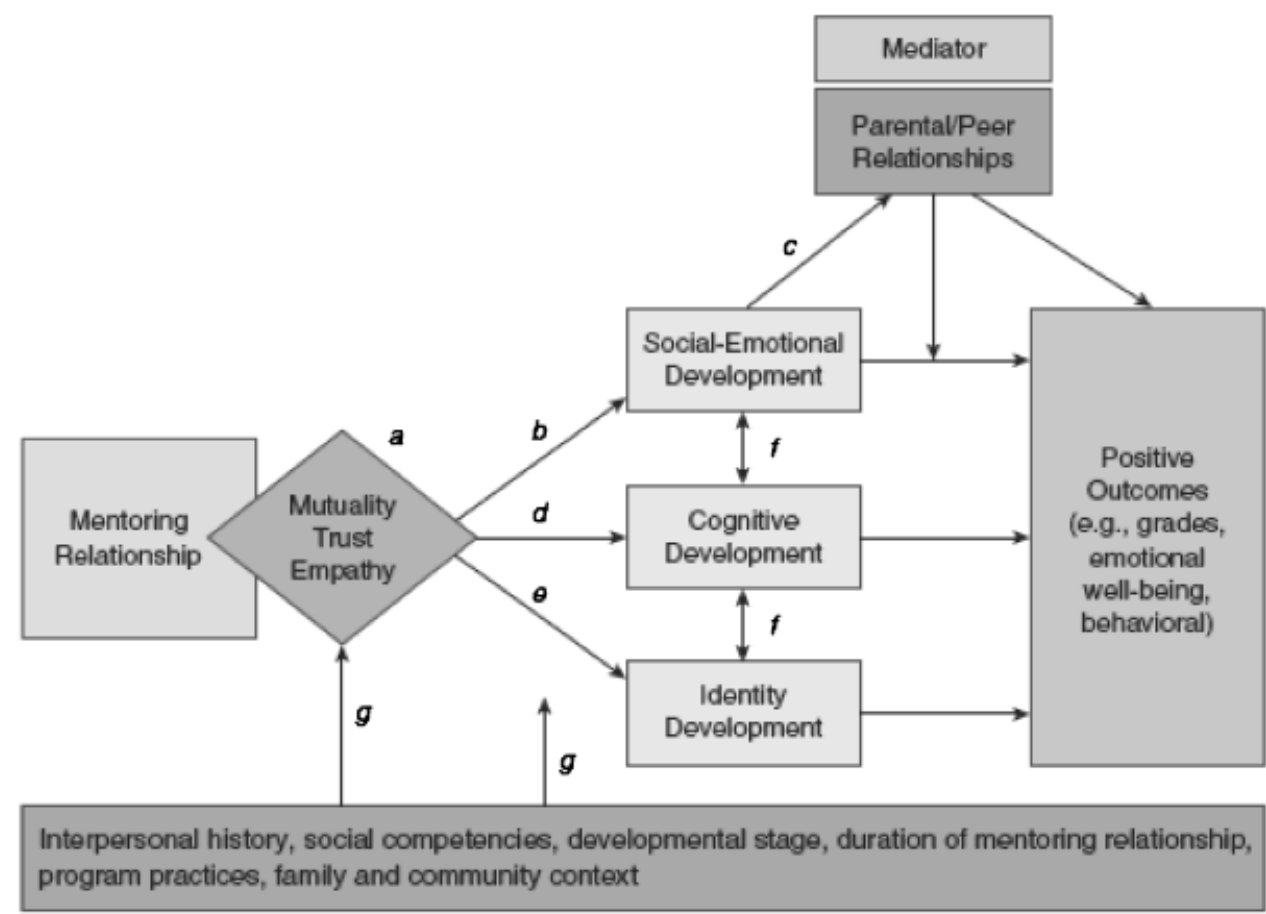

Moderators

Fig. 1. Model of youth mentoring (Rhodes, 2005). Close, enduring mentoring relationships influence youth outcomes through social/emotional, cognitive, and identity development.

skills, becoming more receptive to adult values, advice, and perspectives. In support of these possibilities, close, enduring ties with mentors have been found to predict improvements in academic and vocational outcomes (e.g., Herrera et al., 2007; Klaw, Fitzgerald, \& Rhodes, 2003). Finally, as noted, mentoring relationships also may facilitate identity development (path $e$ ). Illustratively, mentors may help shift youths' conceptions of both their current and future identities. Markus and Nurius (1986) have referred in this regard to "possible selves," or individuals' ideas of what they might become, what they would like to become, and what they fear becoming. More generally, relationships with mentors may open doors to activities, resources, and educational or occupational opportunities on which youth can draw to construct their sense of identity (Darling, Hamilton, Toyokawa, \& Matsuda, 2002). Findings regarding mentors' protective influence on risk behavior (Beier, Rosenfeld, Spitalny, Zanksy, \& Bontempo, 2000) and academic outcomes (Rhodes et al., 2000) are suggestive of a more positive future orientation in their identities. For this type of guidance and support to be realized, however, mentors may need to model appropriate behaviors and values. When youth perceive potential adult mentors to be involved in problem behavior, they are more likely to engage in the same types of behavior themselves (Beam, Gil-Rivas, Greenberger, \& Chen, 2002).

In the theoretical model, both mentoring relationships and the pathways linking them to youth outcomes may be conditioned by a range of individual, family, and contextual influences (see
Fig. 1, $g$ arrows). Several findings are consistent with this assumption. Youth who are overwhelmed by social and behavioral problems, for example, appear to be less likely to experience strong, enduring ties with their mentors and, perhaps consequently, also receive fewer benefits (Rhodes, 2005). Environmental adversities such as family instability and socioeconomic disadvantage also frequently can pose challenges to the formation of mentoring relationships (Spencer, 2007). Yet, youth from backgrounds of environmental risk have been found to be especially likely to benefit from mentoring (DuBois et al., 2002), thus suggesting that the challenges presented by such circumstances need not form barriers to effective relationships.

Returning to the issue of mentoring program effectiveness, it is noteworthy that significantly stronger positive effects on youth have been found when programs have incorporated a range of different practices that would be expected to promote the types of close, enduring, and developmentally enriching relationships that are highlighted as desirable by the preceding theory and research. These practices include training and ongoing supervision of mentors, expectations of relatively frequent meetings and long-lasting relationships between mentors and youth, program-sponsored activities to enhance the development of mentoring relationships, parent support and involvement, and the addition of other programs and services to supplement mentoring (DuBois et al., 2002; Herrera et al., 2007; Jolliffe \& Farington, 2007). In their analysis, DuBois et al. (2002) found that expected effects for programs utilizing the full complement of evidence-based 


\section{BOX 1}

The Across Ages Mentoring Program

One mentoring program, Across Ages, has achieved the status of "model program" on the Substance Abuse and Mental Health Services Administration's National Registry of Evidence-based Programs and Practices. Even as Across Ages has expanded to over 75 sites nationwide, it has continued to demonstrate adherence to its core set of practices, relatively low volunteer attrition, match durations that greatly exceed national averages, and evidence of encouraging behavioral, academic, and psychosocial outcomes (Taylor, LoSciuto, \& Porcellini, 2005). In this program, 10- to 13-year-olds are matched with volunteers aged 50 or older. Volunteers undergo a rigorous screening followed by 10 hours of preservice training. Additional features of Across Ages include:

- Pre-match training of youth

- 1-year commitment (mentors and youth)

- Weekly face-to-face contact for a minimum of 2 hours

- Monthly in-service meetings for mentors for supervision, training and support

- Weekly phone calls to mentors/weekly meetings with youth

- Community service projects

- Structured activities and goal setting

practices that they identified were nearly three times as large as the benefits found for youth in the typical program.

\section{CONCLUSIONS}

Recent research indicates that mentoring programs are likely to be effective to the extent that they are successful in establishing close, enduring connections that promote positive developmental change. Policies that demand greater adherence to evidence-based practice and the use of rigorous evaluations are needed to ensure that quality receives as much attention as does quantity. Models of successful program replication can help guide such growth (see Box 1).

Practices and policies to cultivate greater availability of mentoring relationships for youth are based on the assumption that these ties can offer measurable benefits to young people. Findings from recent research offer support for this viewpoint. Yet there are equally important ways in which the available evidence fails to support current trends in practice and policy. One area of concern is the increasingly broad range of activities-such as tutoring, after-school, and service learning programs - that are argued to constitute mentoring. Underlying this trend seems to be the perspective that any program in which adults are brought into contact with young people may count as providing mentoring regardless of the nature or time frame of the relationships that are involved. Yet, because the processes involved appear to be complex and, in some cases, entail fundamental changes in the ways that children and adolescents think about themselves and their relationships, it should not be assumed that all programs connecting youth with adults would tap into relationship processes in a meaningful or beneficial way.

A second area of concern is that mentoring programs and policies too often have been implemented with insufficient attention to available research. Mentoring strikes deep emotional chords and has attracted powerful constituents who, at some level, have looked to research only to confirm what they intuitively hold to be true. Many organizations and funding sources have adopted aggressive growth goals to increase the numbers of youth mentored. Consequently, largely untested approaches to mentoring (e.g., group, peer, online) have been championed, while existing models have relaxed minimum requirements for volunteer screening, commitment, and training. These approaches have been successful in reducing the burden that is placed on agencies and volunteers yet seem to be directly at odds with the types of practices that research indicates are needed to establish and sustain high-quality mentoring relationships (Rhodes \& DuBois, 2006). In effect, mentoring programs have moved in a direction that is in danger of trivializing what research indicates is at the very heart of their intervention: a caring adult-youth relationship. If youth mentoring relationships are to offer optimal and sustained benefit to young people, theory and research will need to assume a more central role in the development and growth of interventions to cultivate and support such caring relationships between adults and youth.

\section{Recommended Reading}

DuBois, D.L., \& Karcher, M.J. (Eds.). (2005). Handbook of youth mentoring. Thousand Oaks, CA: Sage. A well-organized collection of rigorous, scholarly reviews of theory, research, and practice for a wide range of topics pertaining to youth mentoring.

Hirsch, B.J. (2005). A place to call home: After-school programs for urban youth. Washington, DC: American Psychological Association and New York: Teachers College Press. An in-depth and informative account of mentoring relationships between staff and youth in after-school programs.

Rhodes, J.E. (2002). (See References). A comprehensive, highly accessible overview of what is known about youth mentoring.

Acknowledgments-Both authors are grateful for the support they have received for their research on mentoring and its re- 
lation to practice as Distinguished Fellows of the William T. Grant Foundation.

\section{REFERENCES}

Beam, M.R., Gil-Rivas, V., Greenberger, E., \& Chen, C. (2002). Adolescent problem behavior and depressed mood: Risk and protection within and across social contexts. Journal of Youth \& Adolescence, 31, 343-357.

Beier, S.R., Rosenfeld, W.D., Spitalny, K.C., Zansky, S.M., \& Bontempo, A.N. (2000). The potential role of an adult mentor in influencing high risk behaviors in adolescents. Archives of Pediatrics and Adolescent Medicine, 154, 327-331.

Darling, N., Hamilton, S., Toyokawa, T., \& Matsuda, S. (2002). Naturally occurring mentoring in Japan and the United States: Roles and correlates. American Journal of Community Psychology, 30, $245-270$.

DuBois, D.L., Holloway, B.E., Valentine, J.C., \& Cooper, H. (2002). Effectiveness of mentoring programs for youth: A meta-analytic review. American Journal of Community Psychology, 30, 157-197.

DuBois, D.L., \& Silverthorn, N. (2005). Natural mentoring relationships and adolescent health: Evidence from a national study. American Journal of Public Health, 95, 518-524.

Durlak, J.A., \& Wells, A.M. (1997). Primary prevention mental health programs for children and adolescents: A meta-analytic review. American Journal of Community Psychology, 25, 115-152.

Eby, L.T., Allen, T.D., Evans, S.C., Ng, T.W.H., \& DuBois, D.L. (2008). Does mentoring matter? A multidisciplinary meta-analysis comparing mentored and non-mentored individuals. Journal of Vocational Behavior, 72, 254-267.

Grossman, J.B., \& Rhodes, J.E. (2002). The test of time: Predictors and effects of duration in youth mentoring relationships. American Journal of Community Psychology, 30, 199-219.

Grossman, J.B., \& Tierney, J.P. (1998). Does mentoring work? An impact study of the Big Brothers Big Sisters program. Evaluation Review, 22, 403-426.

Herrera, C., Grossman, J.B., Kauh, T.J., Feldman, A.F., \& McMaken, J. (2007). Making a difference in schools: The Big Brothers Big Sisters school-based mentoring impact study. Philadelphia, PA: Public/ Private Ventures.

Jolliffe, D., \& Farington, D.P. (2007). A rapid evidence assessment of the impact of mentoring on re-offending: A summary. Cambridge University: Home Office Online Report 11/07. http://www. crimereduction.gov.uk/workingoffenders/workingoffenders069.htm

Klaw, E.L., Fitzgerald, L.F., \& Rhodes, J.E. (2003). Natural mentors in the lives of African American adolescent mothers: Tracking relationships over time. Journal of Youth and Adolescence, 32, 322-332.

Langhout, R.D., Rhodes, J.E., \& Osborne, L.N. (2004). An exploratory study of youth mentoring in an urban context: Adolescents' perceptions of relationship styles. Journal of Youth and Adolescence, 33, 293-306.

Markus, H., \& Nurius, P. (1986). Possible selves. American Psychologist, 41, 954-969.

MENTOR. (2006). Mentoring in America 2005: A snapshot of the current state of mentoring. Retrieved August 3, 2007, from http://www. mentoring.org/downloads/mentoring_333.pdf

Morrow, K.V., \& Styles, M.B. (1995). Building relationships with youth in program settings: A study of Big Brothers/Big Sisters. Philadelphia, PA: Public/Private Ventures.

Rhodes, J.E. (2002). Stand by me: The risks and rewards of mentoring today's youth. Cambridge, MA: Harvard University Press.

Rhodes, J.E. (2005). A model of youth mentoring. In D.L. DuBois \& M.J. Karcher (Eds.), Handbook of youth mentoring (pp. 30-43). Thousand Oaks, CA: Sage.

Rhodes, J.E., \& DuBois, D.L. (2006). Understanding and facilitating the youth mentoring movement. Social Policy Report, 20(3), 3-20.

Rhodes, J.E., Grossman, J.B., \& Resch, N.R. (2000). Agents of change: Pathways through which mentoring relationships influence adolescents' academic adjustment. Child Development, 71, 16621671.

Rhodes, J.E., Reddy, R., \& Grossman, J.B. (2005). The protective influence of mentoring on adolescents' substance use: Direct and indirect pathways. Applied Developmental Science, 9, 31-47.

Spencer, R. (2007). "It's not what I expected": A qualitative study of youth mentoring relationship failures. Journal of Adolescent Research, 22, 331-354. 